\title{
Correction to: Localization of myocardial FDG uptake for prognostic risk stratification in corticosteroid-naïve cardiac sarcoidosis
}

\author{
Munehisa Bekki, $M D,{ }^{a}$ Nobuhiro Tahara, $M D, P h D,{ }^{a}$ Atsuko Tahara, $M D,{ }^{a}$ \\ Yoichi Sugiyama, MD, PhD, ${ }^{\text {a }}$ Shoko Maeda-Ogata, MD, ${ }^{a}$ Akihiro Honda, MD, \\ $\mathrm{PhD},{ }^{\mathrm{a}}$ Sachiyo Igata, MD, ${ }^{\mathrm{a}}$ Mika Enomoto, MD, PhD, ${ }^{\mathrm{a}}$ Tatsuyuki Kakuma, MPH, \\ $\mathrm{PhD},{ }^{\mathrm{b}}$ Hayato Kaida, MD, PhD, ${ }^{\mathrm{c}}$ Toshi Abe, MD, PhD, ${ }^{\mathrm{d}}$ and Yoshihiro Fukumoto, \\ $M D, P h D^{a}$ \\ a Division of Cardiovascular Medicine, Department of Medicine, Kurume University School of \\ Medicine, Kurume, Japan \\ b Biostatics Center, Kurume University, Kurume, Japan \\ c Department of Radiology, Faculty of Medicine, Kindai University, Osakasayama, Osaka, Japan \\ d Department of Radiology, Kurume University School of Medicine, Kurume, Japan
}

doi: $10.1007 / \mathrm{s} 12350-021-02740-5$

\section{CORRECTION TO: JOURNAL OF NUCLEAR}

CARDIOLOGY HTTPS://DOI.ORG/10.1007/S12 350-021-02684-W

The original article file and the supplementary material file MOESM2_ESM were published with an incorrect Figure 3A. The original article has been corrected.
Publisher's Note Springer Nature remains neutral with regard to jurisdictional claims in published maps and institutional affiliations.

The original article can be found online at https://doi.org/10.1007/ s12350-021-02684-w.

Reprint requests: Nobuhiro Tahara, MD, PhD, Division of Cardiovascular Medicine, Department of Medicine, Kurume University School of Medicine, 67 Asahi-machi, Kurume830-0011, Japan; ntahara@med.kurume-u.ac.jp

J Nucl Cardiol 2021;28:2361.

$1071-3581 / \$ 34.00$

Copyright (c) 2021 American Society of Nuclear Cardiology. 